cation. Can J Biochem Physiol 37:911-917

14. Morrison WR 1964 A fast, simple and reliable method for the micro-determination of phosphorus in biological materials. Anal Biochem 11:218-224

15. Mason RJ, Nellenbogen J, Clements JA 1976 Isolation of disaturated phosphatidylcholine with osmium tetroxide. J Lipid Res 17:281-284

16. Weibel ER 1963 In: Morphometry of Human Lung. Academic Press Inc, New York, pp 1-39

17. Scherle W 1970 A simple method for volumetry of organs in quantitative stereology. Mikroskopie 26:57-60

18. Steel RGD, Torrie JH 1960 Principles and Procedures of Statistics. McGraw Hill, New York, pp 67-98, 366-387

19. Litchfield JT Jr, Wilcoxon F 1949 A simplified method of evaluating doseeffect experiments. J Pharmacol Exp Ther 96:99-113

20. Miller HC $1983 \mathrm{~A}$ model for studying the pathogenesis and incidence of lowbirth-weight infants. Am J Dis Child 137:323-327

21. Evans MI, Lin C-C 1984 Retarded fetal growth. In: Lin C-C, Evans MI (eds) Intrauterine Growth Retardation. McGraw Hill, New York, pp 55-77

22. Mulay S, Browne CA, Varma DR, Solomon S 1980 Placental hormones, nutrition, and fetal development. Fed Proc 39:261-265

23. Van Geijn GP, Kaylor WM Jr, Nicola KR, Zuspan FP 1980 Induction of severe intrauterine growth retardation in the Sprague-Dawley rat. Am J Obstet Gynecol 137:43-47

24. Gunn T, Reaman G, Outerbridge EW, Colle E 1978 Peripheral total parenteral nutrition for premature infants with the respiratory distress syndrome: a controlled study. J Pediatr 92:608-613

25. Roberts RJ 1978 Implications of nutrition in oxygen-related pulmonary disease in the human premature infant. Adv Pharmacol Ther 8:53-64

26. Hackney JJ, Evans MJ, Bils RF, Spier CE, Lones MP 1977 Effects of oxygen at high conentrations and food deprivation on cell division in lung alveoli of mice. Exp Mol Pathol 26:350-358
27. Polgar G, Antagnoli W, Ferrigan LW, Martin EA, Gregg WP 1966 The effect of chronic exposure to $100 \%$ oxygen in newborn mice. Am J Med Sci 112:580-587

28. Massaro D, Massaro GD 1978 Biochemical and anatomical adaptation of the lung to oxygen-induced injury. Fed Proc 37:2485-2488

29. Gross NJ, Smith DM 1981 Impaired surfactant phospholipid metabolism in hyperoxic mouse lungs. J Appl Physiol 51:1198-1203

30. Huber RL, Drath DB 1981 Pulmonary oxygen toxicity. In: Gilbert DL (ed) Oxygen and Living Processes. An Interdisciplinary Approach. SpringerVerlag, New York, pp 273-324

31. Frank L, Massaro D 1980 Oxygen toxicity. Am J Med 60:117-126

32. Freeman BA, Crapo JD 1982 Biology of disease. Free radicals and tissue injury. Lab Invest 47:412-426

33. Deneke SM, Fanburg BL 1983 Effect of transient decrease in glutathione on rat oxygen toxicity. Am Rev Respir Dis 127:284

34. Scopes JW, Ahmed I 1966 Minimal rates of oxygen consumption in sick and premature newborn infants. Arch Dis Child 41:407-416

35. Sauer PJJ, Dane HJ, Visser HKA 1984 Longitudinal studies on metabolic rate, heat loss, and energy cost of growth in low birth weight infants. Pediatr Res 18:254-259

36. Hawrylewicz EJ, Kissane JQ, Blair WH, Heppner CA 1973 Effect of maternal protein malnutrition on neonatal lung development and mitochondrial function. Nutr Rep Int 7:253-269

37. Roux JM 1971 Decrease in the rate of DNA synthesis in newborn rats with intrauterine growth retardation. Biol Neonate 18:463-467

38. Faridy EE 1975 Effect of maternal malnutrition on surface activity of fetal lungs in rats. J Appl Physiol 39:535-540

39. Morand O, Chanez C, Masson M, Dumont O, Flexor MA, Baumann N, Bourre JM 1982 Alteration in fatty acid composition of neurons, astrocytes, oligodendrocytes, myelin and synaptosomes in intrauterine malnutrition in rat. Ann Nutr Metab 26:111-120

\title{
Composition and Surface Activity of Normal and Phosphatidylglycerol-Deficient Lung Surfactant
}

\author{
MIKKO HALLMAN, GORAN ENHORNING, AND FRED POSSMAYER \\ Department of Pediatrics, University of Helsinki, 00290 Helsinki 29, Finland, and University of California, San \\ Diego, La Jolla, California 92093 [M.H.], Departments of Obstetrics and Gynaecology, University of Toronto, \\ Toronto, Ontario, Canada MST 2S8 [G.E.], and University of Western Ontario,
}

London, Ontario, Canada N6A 5 A5 [F.P.]

\begin{abstract}
The possibility that pulmonary surfactant, characterized by a phosphatidylglycerol deficiency, as in early fetal life, might have inferior surface properties was evaluated. We obtained this specific surfactant from adult rabbits by withholding glucose and giving them an excess of myoinositol by mouth and intravenously. Controls were given a similar quantity of glucose. The myoinositol resulted in a drastic reduction of surfactant phosphatidylglycerol, from 7.2 to $0.3 \%$ of phospholipids, and a corresponding increase in phosphatidylinositol from 4.8 to $11.3 \%$. In addition, the myoinositol treatment increased the myoinositol that was disaturated from 18.5 to $27.3 \%(p<0.05)$. The corresponding figures for disaturated phosphatidyl-
\end{abstract}

Received June 12, 1984; accepted October 24, 1984.

Requests for reprints should be addressed to Mikko Hallman, M.D., Children's Hospital, University of Helsinki, Stenbäckinkatu 11, 00290 Helsinki 29, Finland.

Supported by grants from the Finnish Academy, the Juselius Foundation (M.H.) a United States Public Health Service Grant (HD-04380 to Louis Gluck), and the Medical Research Council of Canada (Grant MT-4497 to G.E.). choline were 56.0 and $60.5 \%$, respectively (NS). The myoinositol treatment for $\mathbf{4}$ days increased the pool size of alveolar surfactant by $32 \%(p<0.01)$. The surface activity was studied with modified Wilhelmy balance and the pulsating bubble surfactometer. Surfactant containing phosphatidylinositol rather than phosphatidylglycerol was not inferior, as compared to surfactant that contained phosphatidylglycerol (minimum surface tension: 2.0 versus 2.2 $\mathrm{mN} \cdot \mathrm{m}^{-1}$; collapse rate at $10 \mathrm{nM} \cdot \mathrm{m}^{-1}$ : 1.85 versus 1.95 $\min ^{-1}$; rate of adsorption from subphase to surface: 32 versus $35 \mathrm{mN} \cdot \mathrm{m}^{-1} \cdot 30 \mathrm{~s}^{-1}$ ), nor was there a difference in the ability of the two surfactants to improve lung stability of 27-day-old rabbit fetuses (air retention at $35 \mathrm{~cm} \mathrm{H}_{2} \mathrm{O}$ : 1.8 versus $1.8 \mathrm{ml} / 30 \mathrm{~g}$; air retention at $0 \mathrm{~cm} \mathrm{H} \mathrm{H}_{2} 0: 0.8$ versus $0.9 \mathrm{ml} / 30 \mathrm{~g}$ ). We conclude that phosphatidylinositol surfactant does not have inferior surface properties. Myoinositol affects not only the acidic surfactant phospholipids but also increases the pool size of surfactant by an as yet unknown mechanism. (Pediatr Res 19: 286-292, 1985) 


\section{Abbreviations}

DPPC, dipalmitoyl phosphatidylcholine

PC, phosphatidylcholine

PG, phosphatidylglycerol

PE, phosphatidylethanolamine

PI, phosphatidylinositol

A main and very active component of pulmonary surfactant is DPPC. There are also other phospholipids present: monounsaturated PC, PG, PE, and PI. Free fatty acids, triglycerides, and cholesterol are also found in small quantities, and there is at least one specific protein (23). The composition of pulmonary surfactant appears rather similar among various mammalian species but can be affected by the serum concentration of myoinositol, a hexahydroxy derivative of cyclohexane. A high concentration of this sugar alcohol suppresses PG synthesis and correspondingly increases the PI content of surfactant in adult animals, in vivo as well as in vitro $(3,5,16)$. In pregnancy, the fetal surfactant synthesis may be similarly affected, since the serum concentration of myoinositol may be up to 20 times higher than in the adult and permeability into alveolar cells may be increased (6, $31)$. These circumstances explain that in surfactant from immature fetuses PI is detectable, but PG is not. The effluent from airways of infants suffering from the respiratory distress syndrome is characterized by the presence of PI and the absence of PG, and it has been suggested that PG specifically improves the surfactant quality (18), but it is also possible that the appearance of this phospholipid in the lung effluent of a fetus near term merely indicates an overall maturity of the lung, including a larger size surfactant pool (13).

The purpose of this study was to clarify whether surface properties, as they affect lung expansion and stability, are inferior when the surfactant lacks PG but contains correspondingly more PI. Pulmonary surfactant from normal adult rabbits was compared with that synthesized in rabbits with a high serum myoinositol concentration.

\section{MATERIALS AND METHODS}

Obtaining rabbit surfactant. Male, New Zealand rabbits weighing $1.2 \pm 0.1 \mathrm{~kg}$, were used. Their food intake was ad libitum, but with the drinking water, and with two separate intravenous infusions, the animals also received either myoinositol or glucose.

Water was totally withheld for 14 to $16 \mathrm{~h}$ prior to the first infusion with a sterile solution of either glucose or myoinositol (Sigma, Inc., St. Louis, MO). The concentration of the solutions was $10 \%(\mathrm{w} / \mathrm{v})$ or, since the molecular weight of both sugars is about $180,0.56 \mathrm{M}$. The infusion, lasting approximately $3 \mathrm{~h}$, was given into an ear vein in a volume of $40 \mathrm{ml} / \mathrm{kg}$. The rabbits were then allowed to drink again, but only a $4 \%$ solution of the same kind of sugar that was used for the infusion, glucose or myoinositol. Only animals drinking more than $80 \mathrm{ml} / \mathrm{kg} /$ day were included in the study. Two to four days after the first infusion with glucose or myoinositol, they received a second identical infusion, before and after which free serum myoinositol was analyzed with gas-liquid chromatography (15).

Surfactant was recovered 14 to $16 \mathrm{~h}$ following completion of the second infusion. The animals received ketamine hydrochloride $(45 \mathrm{mg} / \mathrm{kg})$ and xylazine $(15 \mathrm{mg} / \mathrm{kg})$ and were bled through ear arteries. The trachea was cannulated under local anesthesia and the lungs lavaged five times with $0.9 \% \mathrm{NaCl}(15-18 \mathrm{ml} / \mathrm{kg}$ for each lavage). The liquid obtained was centrifuged at $150 \times g$ for $10 \mathrm{~min}$. This and all subsequent steps took place at 0 to $4^{\circ}$ C. Any lavage with visible blood contamination was discarded. The supernatant was centrifuged at $7500 \times g$ for $120 \mathrm{~min}$. The resulting pellet was resuspended in $0.9 \% \mathrm{NaCl}$ and layered over a discontinuous density gradient containing $0.6 \mathrm{M}$ sucrose, 20
$\mathrm{mM} \mathrm{NaCl}, 10 \mathrm{mM}$ Tris-HCl, $0.1 \mathrm{mM}$ EDTA (pH 7.4), and 0.27 $\mathrm{M}$ sucrose-NaCl-Tris-EDTA. After centrifugation at $10^{5} \times \mathrm{g}$ in an SW 27 rotor for $90 \mathrm{~min}$, an interphase which developed between the two sucrose layers was collected, diluted with a large excess of distilled water, and subsequently centrifuged at $7500 \times$ $g$ for $120 \mathrm{~min}$. The pellet was dispersed in water and a known volume of the suspension was freeze-dried so it could be shipped overseas.

Biochemical methods. The phospholipids and neutral lipids were analyzed as described previously (17-19). To improve the separation between PI and PC, two-dimensional thin-layer chromatography was used and the second direction was run twice. For further analysis of the phospholipids, the appropriate lipid spots were eluted from the silica gel after they had been visualized by spraying with water or methanol.

The phospholipid's fatty acid distribution was analyzed with gas-liquid chromatography, usng a Perkin-Elmer instrument with a column packed with $10 \%$ Silar $10 \mathrm{C}$ on $100 / 120$ Mesh Gas ChromQ (Applied Science Laboratories, State College, PA). The carrier gas was $\mathrm{N}_{2}$ and the isothermal temperature $180^{\circ} \mathrm{C}$. The fatty acid methyl esters were identified using appropriate standards and mass spectrometry. The areas under the peaks were integrated with an $\mathbf{M}_{2}$ Perkin-Elmer integrator. For analysis of the distribution of the fatty acids, the phospholipids were first treated with phospholipase $\mathrm{A}_{2}$ (Crotalus adamanteus, Sigma), followed by analysis of the lysophospholipids and the free fatty acids. Saturated PC was quantified according to Mason et al. $(17,27)$.

The molecular classes of the phospholipids were further analyzed, essentially as described by Okano and Akino (35). Using phospholipase C from Bacillus cereus and Clostridium welchii (Sigma), the phospholipids were converted into 1,2-diacylglycerols (36), which were then extracted with ether from the incubation mixture. The dry extracts were immediately acetylated with acetic anhydride and anhydrous pyridine. The diacylglycerol acetates were recovered and purified as described by Kuksis et al. (26), and according to their degree of saturation they were resolved into molecular species by means of argentation thinlayer chromatography. Silica gel $\mathrm{H}$ plates containing $10 \% \mathrm{AgNO}_{3}$ were first developed to a height of $8 \mathrm{~cm}$ with chloroform/ methanol $(95: 5 \mathrm{v} / \mathrm{v})$, dried, and then developed to $20 \mathrm{~cm}$ with chloroform. The diacylglycerol acetates were recovered from the gel by the method of Arvidson (1). The fractions were analyzed for fatty acids by gas-liquid chromatography, using pentadecanoic acid as an internal standard. This allowed both qualitative identification of the molecular subclasses and quantitative analysis of the distribution of individual molecular subclasses.

Surface activity assessment. A Wilhelmy balance was used with a tight-fitting Teflon barrier, as described by Hildebran et al. (20). A temperature of $36.7 \pm 0.3^{\circ} \mathrm{C}$ was maintained, and the subphase contained $5 \mathrm{mM}$ Tris- $\mathrm{HCl}, 154 \mathrm{mM} \mathrm{NaCl}, 2 \mathrm{mM}$ $\mathrm{CaCl}_{2}$, and $1 \mathrm{mM} \mathrm{MgCl}$ ( $\mathrm{mH}$ 7.4). To avoid leaks with surface compression, the inside walls of the trough were treated with $\mathrm{LaCl}_{3}$-DPPC (20). Dry surfactant containing $250 \mathrm{nmol}$ phospholipid phosphorus was applied to the surface of $444 \mathrm{~cm}^{2}$. From this maximal size, the surface area was cyclically compressed to a minimum of $40 \mathrm{~cm}^{2}$ at a constant rate of $\mathrm{cm}^{2} . \mathrm{s}^{-1}$, and area/ surface tension isotherms were obtained with an $\mathrm{X} / \mathrm{Y}$ recorder. The collapse rate $\left(K_{m}\right)$ of the film kept at minimum area was calculated according to Hildebran et al. (20): $\mathrm{K}_{\mathrm{m}}=1 /\left(\gamma_{\mathrm{eq}}-\gamma\right)$ $\times \mathrm{d} \gamma / \mathrm{dt}$; where $\gamma_{\mathrm{eq}}=$ equilibrium surface tension $\left(26 \mathrm{mN} \cdot \mathrm{m}^{-1}\right)$; $\gamma=10 \mathrm{mN} / \mathrm{m} ; \mathrm{d} \gamma / \mathrm{dt}=$ rate of increase in surface tension at 10 $\mathrm{mN} / \mathrm{m}$. The lowest compressibility $\left(\mathrm{C}_{\mathrm{m}}\right)$ at $10 \mathrm{mN} / \mathrm{m}$ was calculated as follows: $C_{m}=(1 / A) \times(d A / d \gamma)$; where $A=$ surface area at $10 \mathrm{mN} / \mathrm{m}$.

The recruitment index was calculated according to Notter et al. (33): recruitment index $=\left[\gamma_{\min }+(\Delta \gamma)\right] / \gamma_{\min }$, where $\gamma_{\min }=$ minimum surface tension; $\Delta \gamma=$ surface tension change over the first $5 \%$ of the total expansion cycle.

The principle of the pulsating bubble surfactometer is to 
continuously record pressure around a bubble, communicating with ambient air through a capillary and pulsating in the liquid to be examined (9). The bubble radius, $r$, cyclically varies in size from a maximum of $0.55 \mathrm{~mm}$ to a minimum of $0.4 \mathrm{~mm}$. When the pressure difference across the bubble surface, $\Delta \mathrm{P}$, is known, as well as the corresponding value of $r$, which is measured with the greatest accuracy at maximal and minimal bubble size, then surface tension, $\gamma$, can be calculated from the law of Laplace: $\Delta \mathrm{P}=2 \gamma / \mathrm{r}$. The freeze-dried surfactant was suspended by vortexing in $100 \mathrm{mM} \mathrm{NaCl}$ and $2 \mathrm{mM} \mathrm{CaCl}$ and the phospholipids were given a concentration of 10 or $2 \mu \mathrm{mol} / \mathrm{ml}$. For evaluation with the bubble surfactometer, the $20 \mu \mathrm{l}$ sample chamber was filled with this suspension and, while the recorder was running, a bubble was quickly expanded and made to pulsate at $20 \mathrm{rpm}$. The speed with which $\Delta \mathrm{P}$ diminished after bubble creation reflected the rate of monolayer formation, i.e. adsorption rate. The temperature was $37^{\circ} \mathrm{C}$.

The ability of the two types of surfactant to facilitate lung expansion and maintain stability was assessed by instilling the surfactant into the trachea of the preterm rabbit neonates. When the pregnancy had reached the age of 27 days and 16 to $20 \mathrm{~h}$,

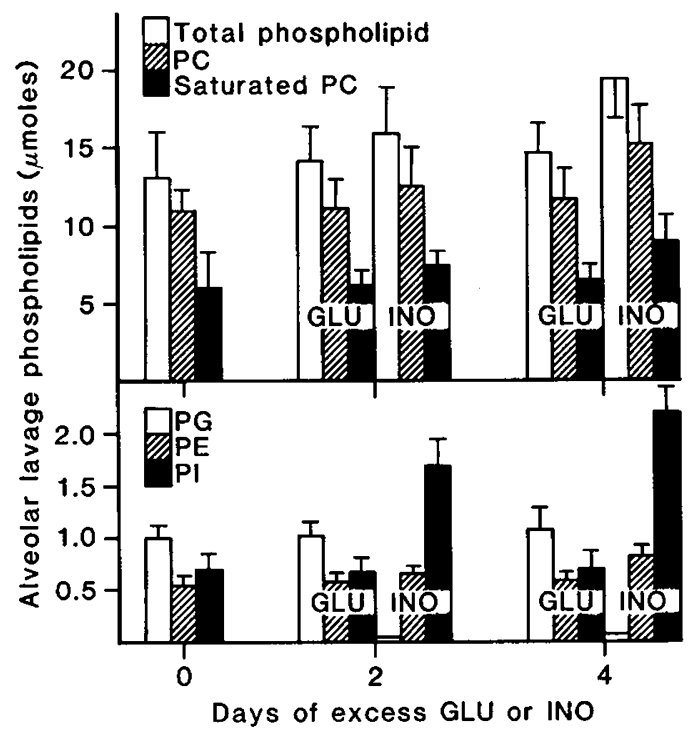

Fig. 1. The effect of the glucose $(G L U)$ or the myoinositol (INO) treatment on the recovery of surfactant phospholipids in alveolar lavage. The results are given as mean \pm SD of five to eight assays. Myoinositol for 4 days significantly increased surfactant phospholipids $(p<0.02)$, except PG. the does were sacrificed with a fast iv injection of $10 \mathrm{ml}$ thiopental sodium $(20 \mathrm{mg} / \mathrm{ml})$. The abdomen was opened immediately, and through the uterine wall the fetuses were injected intracranially with $10 \mathrm{mg}$ thiopental sodium. This prevented them from gasping when delivered. The trachea was cannulated with a metal tube, length $12 \mathrm{~mm}$, OD $1.25 \mathrm{~mm}$. By holding up the hind legs of the rabbit pups, pulmonary fluid was made to flow from the metal tube via a fine polyethylene catheter directly into a sample chamber of the bubble surfactometer. Assessing surface properties of the pulmonary fluid from each neonate individually offered evidence that those tested with one surfactant were no different from those tested with the other, and both groups had immature lungs.

Lung expansion, as affected by the two types of surfactant, was studied simultaneously in all neonates of a litter, using the method of Enhorning and Robertson (10). A polyethylene catheter with $25 \mu \mathrm{l}$ surfactant suspension, or $25 \mu \mathrm{l}$ of saline, was connected to the metal tracheal tube, making sure that the pulmonary fluid in the latter and the surfactant were in direct contact with no air in between. The other end of the catheter communicated, via a horizontal glass tube containing $2 \mathrm{ml}$ air, with a water reservoir. The latter was raised stepwise to a height of $10,20,30$, and $35 \mathrm{~cm}$ and then lowered to $30,20,10$, and 0 $\mathrm{cm}$. Since each level of pressure thus created equally affected all neonates of a litter and was maintained for $15 \mathrm{~s}$, it required 2 min to obtain the inflation-deflation curves for the whole litter. The newborn dead rabbits were all immersed just under the surface of water kept at $37^{\circ} \mathrm{C}$. Air moving into lungs from any of the corresponding parallel glass tubes would be replaced with water from the reservoir. The increase in the amount of water in the horizontal glass tubes was recorded photographically and corresponded to the volume of air in a pair of lungs. For the final analysis, the air volume was related to $30 \mathrm{~g}$ body weight, the average for rabbits at a gestational age of 27 days.

Other methods. The results were expressed as mean $\pm \mathrm{SD}$. The statistical significance was calculated using one-way analysis of variance and the $t$ test.

Table 2. The percentage composition of the molecular subclasses of the $P C$

\begin{tabular}{lcc}
\hline & $\begin{array}{c}\text { PG-surfactant } \\
(n=5)\end{array}$ & $\begin{array}{c}\text { PI-surfactant } \\
(n=5)\end{array}$ \\
\hline Saturated & $56.0 \pm 6.0$ & $60.5 \pm 7.2$ \\
Monounsaturated & $30.5 \pm 2.2$ & $28.5 \pm 3.3$ \\
Diunsaturated & $8.5 \pm 3.5$ & $7.3 \pm 1.2$ \\
Polyunsaturated & $5.0 \pm 2.9$ & $4.0 \pm 3.0$ \\
\hline
\end{tabular}

Table 1. The percentage fatty acid composition of the neutral phospholipids in PG-and PI-surfactant

\begin{tabular}{|c|c|c|c|c|}
\hline & \multicolumn{2}{|c|}{ PG-surfactant $(n=5)$} & \multicolumn{2}{|c|}{ PI-surfactant $(n=5)$} \\
\hline & PC & $\mathrm{PE}$ & PC & $\mathrm{PE}$ \\
\hline 14:0 & $1.2 \pm 0.4(1.6, \mathrm{ND})^{*}$ & $2.0 \pm 0.4$ & $1.2 \pm 0.5(1.2, \mathrm{ND})$ & $0.9 \pm 0.5$ \\
\hline $14: 1$ & $0.5 \pm 0.1(0.7, \mathrm{ND})$ & $1.0 \pm 0.6$ & ND & $1.3 \pm 0.4$ \\
\hline $16: 0$ & $69.5 \pm 3.6(84.8,53.1)$ & $27.5 \pm 3.5$ & $72.1 \pm 4.7(87.2,57.6)$ & $28.0 \pm 3.2$ \\
\hline $16: 1$ & $6.5 \pm 0.8(3.4,9.6)$ & $9.0 \pm 1.0$ & $6.0 \pm 1.1(3.3,8.2)$ & $8.2 \pm 0.6$ \\
\hline 18:0 & $4.0 \pm 0.3(2.4,5.2)$ & $10.6 \pm 0.7$ & $4.5 \pm 0.5(3.6,6.7)$ & $12.4 \pm 1.0$ \\
\hline $18: 1$ & $14.0 \pm 1.9(6.3,24.5)$ & $29.7 \pm 2.9$ & $12.8 \pm 2.0(4.1,22.0)$ & $30.0 \pm 2.8$ \\
\hline $18: 2$ & $4.3 \pm 1.0(0.8,7.5)$ & $16.8 \pm 2.9$ & $3.4 \pm 1.2(0.6,6.4)$ & $15.7 \pm 2.0$ \\
\hline $20: 1$ & ND & $1.8 \pm 0.7$ & ND & $1.6 \pm 1.0$ \\
\hline $20: 4$ & ND & $0.8 \pm 0.8$ & ND & $1.0 \pm 0.4$ \\
\hline Unidentified & ND & $0.8 \pm 0.6$ & ND & $0.9 \pm 0.5$ \\
\hline Saturated & $74.7 \pm 3.6(88.8,58.3)$ & $40.1 \pm 3.9$ & $77.8 \pm 4.7(92.0,64.3)$ & $41.3 \pm 4.0$ \\
\hline Monounsaturated & $21.0 \pm 2.0(10.4,34.1)$ & $39.7 \pm 3.0$ & $18.8 \pm 2.9(7.4,30.2)$ & $41.1 \pm 3.6$ \\
\hline
\end{tabular}

* The figures in the parentheses indicate the percentage of the fatty acyl moieties associated with 1-, and 2-position, respectively. ND means less than $0.5 \%$ of the total fatty acids. 
Table 3. The percentage fatty acid composition of the acidic phospholipids in PG-and PI-surfactant

\begin{tabular}{|c|c|c|c|c|}
\hline & \multicolumn{3}{|c|}{ PG-surfactant $(n=5)$} & \multirow{2}{*}{$\frac{\text { PI-surfactant }(n=5)}{\text { PI }}$} \\
\hline & PG & PI & $\mathrm{PG}+\mathrm{PI}$ & \\
\hline $14: 0$ & $3.0 \pm 0.7(4.5,1.8)$ & $1.2 \pm 0.4(1.1,1.3)$ & $2.3 \pm 0.5(3.1,1.6)$ & $1.2 \pm 0.1(1.5,2.0)$ \\
\hline $16: 0$ & $53.2 \pm 2.4^{1}(61.6,47.3)$ & $35.1 \pm 1.9^{1,2}(45.2,26.2)$ & $46.0 \pm 2.0(55.0,38.9)$ & $47.0 \pm 2.7^{2}(54.0,39.0)$ \\
\hline $16: 1$ & $10.2 \pm 0.9(10.4,10.1)$ & $9.8 \pm 0.7(9.8,9.2)$ & $10.0 \pm 0.8(10.2,9.7)$ & $9.1 \pm 0.4(8.5,10.6)$ \\
\hline $18: 0$ & $10.3 \pm 1.3^{1}(12.5,8.5)$ & $16.7 \pm 2.0^{1,2}(20.0,13.1)$ & $12.9 \pm 2.1(15.5,10.3)$ & $12.8 \pm 1.1^{2}(17.9,6.9)$ \\
\hline $20: 1$ & ND & $0.9 \pm 0.4(\mathrm{ND}, 1.3)$ & ND & ND \\
\hline $20: 4$ & ND & ND & ND & ND \\
\hline Unidentified & $0.9 \pm 0.4(0.8,0.9)$ & $2.4 \pm 0.9$ & $1.5 \pm 0.5(0.8,2.1)$ & $1.8 \pm 0.7(0.5,3.3)$ \\
\hline Saturated & $66.5 \pm 2.9^{1}(78.6,57.6)$ & $53.0 \pm 4.0^{1,2}(66.3,40.6)$ & $61.2 \pm 3.2(73.7,50.8)$ & $61.0 \pm 3.4^{2}(73.4,48.9)$ \\
\hline Monounsaturated & $28.6 \pm 1.6(19.4,34.7)$ & $37.9 \pm 3.2(28.8,46.4)$ & $32.1 \pm 2.9(23.6,39.4)$ & $31.8 \pm 2.3(22.1,40.9)$ \\
\hline
\end{tabular}

The identical superscripts on the same line indicate that the two groups differ significantly $(p<0.02)$ from each other. For other information see Table 1.

Table 4. The percentage composition of the molecular classes of the acidic surfactant phospholipids

\begin{tabular}{lrrrrr}
\hline & \multicolumn{3}{c}{ PG-surfactant $(n=4)$} & & $\begin{array}{c}\text { PI-surfac- } \\
\text { tant } \\
(n=4)\end{array}$ \\
\cline { 2 - 4 } & PG & PI & PG + PI & PI \\
\hline Saturated & $31.5 \pm 5.3^{1}$ & $18.5 \pm 3.0^{1,2}$ & $26.3 \pm 4.4$ & $27.3 \pm 3.9^{2}$ \\
Monoenoic & $52.8 \pm 7.4$ & $62.3 \pm 6.7$ & $56.6 \pm 7.5$ & $52.9 \pm 4.2$ \\
Dienoic & $13.3 \pm 6.2$ & $14.1 \pm 2.9$ & $13.6 \pm 5.5$ & $15.0 \pm 3.8$ \\
Polyenoic & $2.4 \pm 1.0$ & $5.1 \pm 4.0$ & $3.5 \pm 1.4$ & $4.8 \pm 1.9$ \\
\hline
\end{tabular}

The identical superscripts on the same line indicate that the two groups differ significantly $(p<0.05)$ from each other.

\section{RESULTS}

Serum myoinositol shortly before and 12 to $14 \mathrm{~h}$ after the second intravenous infusion was $2.15 \pm 0.40$ and $3.67 \pm 0.69$ $\mathrm{mM}$, respectively. The controls, receiving glucose, had a myoinositol concentration in serum of only $62 \pm 9 \mu \mathrm{M}$.

Lipid composition. Figure 1 shows the phospholipid recovery in the total but cell-free alveolar lavage. Following myoinositol treatment for 4 days, all surfactant phospholipids, except PG, increased, whereas glucose infusion had no detectable effect on phospholipid pool size or distribution. The myoinositol treatment had a dramatic effect on the acidic phospholipids. Thus, PG decreased from $7.2 \pm 0.9$ to $0.3 \pm 0.3 \%$ of total phospholipids, and PI increased from $4.8 \pm 0.7$ to $11.3 \pm 2.9 \%$.

Tables 1 and 2 show data on the fatty acid structure of the nonacidic phospholipids PC and PE. There is a higher percentage of saturated species in PC than in PE, but the fatty acid structure of these two nonacidic phospholpids was not affected by the myoinositol treatment.

Tables 3 and 4 show data on the fatty acid structure of the acidic phospholipids PG and PI. In the PG surfactant, i.e. the surfactant originating from glucose-infused rabbits, PG contained relatively more palmitic acid than did PI but less stearic and oleic acids. The PI surfactant, i.e. the surfactant originating from myoinositol-treated rabbits had more palmitic but less stearic and oleic acids. Myoinositol treatment significantly increased the saturated fatty acids of PI. The comparison of PG and PI surfactant shows that there was no detectable difference in the fatty acid structure of the total acidic phospholipids.

Surface properties. The in vitro surface properties as evaluated with the Wilhelmy balance and with the bubble surfactometer are reported with Table 5. PG and PI surfactants were very similar and fulfill all criteria reportedly typical to lung surfactant.
Figure 2 illustrates typical area to surface tension isotherms of PG and PI. There is a small but significant difference which is also reflected in the recruitment index (Table 5).

With the pulsating bubble surfactometer, it was found that both types of surfactant had a fast adsorption rate. As soon as the bubble was expanded, a surface tension of 30 to $35 \mathrm{mN} / \mathrm{m}$ was recorded. During an "expiration" surface tension decreased and in the first cycle reached a value of 5 to $10 \mathrm{mN} / \mathrm{m}$. After 1 min of pulsation, the lowest value of surface tension, coinciding with minimal bubble size, was close to zero (Fig. 3).

When the two types of surfactant were instilled into the upper airways of immature lungs, the pressure-volume loops obtained were almost identical (Fig. 4). There was little if any air expansion, hysteresis, or air retention at $0 \mathrm{~cm} \mathrm{H}_{2} \mathrm{O}$ when saline instead of surfactant was instilled to the airways.

\section{DISCUSSION}

With the present study, we have confirmed that by replacing glucose intake with myoinositol it is possible to alter the surfactant lipid composition of an adult animal toward that found in fetal life $(16,18)$. The surfactant originating from the rabbits receiving glucose by mouth and intravenously was similar to that of normal adult surfactant, containing PG as well as PI. On the other hand, rabbits receiving myoinositol by mouth and as an intravenous infusion had barely any PG in their surfactant, but did have correspondingly increased PI. The ratio between these acidic phospholipids was similar to what characterizes surfactant of early fetal life when the concentration of serum myoinositol is high. The myoinositol treatment resulted in an increased surfactant pool, but had no detectable effect on the relative concentration of other components than PG and PI.

In addition, the myoinositol treatment increased the saturated fatty acid moieties (especially palmitate) of PI, and the fatty acid structure of PI approached that of PG. Therefore, the myoinositol treatment did not significantly affect the fatty acid structure of the total acidic surfactant phospholipids (PG + PI), although there were severe perturbations in the individual acidic phospholipids. This is in accordance with the proposal that PG and PI derive the fatty acid moieties from a common CDP-diacylglycerol pool (16).

A previous study demonstrated that PI surfactant from fetal rabbit lung was surface active (18). However, it had a higher compressibility at low surface tensions than had PG surfactant from postnatal lung, suggesting a poor capacity to stabilize alveoli during expiration. Isolation of surfactant from lungs at different developmental stages may result in unpredictable nonsurfactant contamination, and several subtle differences in composition 
Table 5. Comparison of the surface properties of $P G$ and PI-surfactants

\begin{tabular}{lcc}
\hline & PG-surfactant & PI-surfactant \\
\hline Wilhelmy balance & & $2.0 \pm 0.8(7)$ \\
Minimum surface tension $(\mathrm{mN} / \mathrm{m})$ & $2.2 \pm 0.2(7)^{*}$ & $0.032 \pm 0.001$ \\
Lowest compressibility at $10 \mathrm{mN} / \mathrm{m}$ & $0.035 \pm 0.012$ & $1.05 \pm 0.06$ \\
$\quad(\mathrm{~m} / \mathrm{mN})$ & $1.04 \pm 0.4$ & $16.0 \pm 1.9$ \\
Surface concentration of phospholipid & & $1.85 \pm 0.2$ \\
$\quad$ at $10 \mathrm{mN} / \mathrm{m}\left(\mathrm{nmol} / \mathrm{cm}^{2}\right)$ & $13.2 \pm 1.3$ & \\
Recruitment index & $1.95 \pm 0.4$ & \\
Collapse rate at $10 \mathrm{mN} / \mathrm{m}(1 / \mathrm{min})$ & & $14(3), \dagger 32(2) \ddagger$ \\
Decrease in surface tension during ad- & & 20,37 \\
$\quad$ sorption from subphase to sur- & & 34,36 \\
phase & $12(3), \dagger 35(2) \ddagger$ & \\
$\Delta$ mN/m after: & 25,37 & \\
$30 \mathrm{~s}$ & 32,32 & \\
2 min & & $15(2), \S 7(3) \|$ \\
5 min & & 2,0 \\
Pulsating bubble surfactometer & & 0,0 \\
Minimum surface tension & & \\
mN/m after: & $14(2), \S 6(3) \|$ & 5,0 \\
1 st pulse & 1,0 & \\
$15 \mathrm{~s}$ & & \\
$30 \mathrm{~s}$ & & \\
\hline
\end{tabular}

* Mean \pm SD (number of assays).

$\dagger$ The concentration of surfactant phospholipid $25 \mathrm{nmol} / \mathrm{ml}$. $\$$ The concentration of surfactant phospholipid $100 \mathrm{nmol} / \mathrm{ml}$. $\S$ The concentration of surfactant phospholipid $2 \mu \mathrm{mol} / \mathrm{ml}$. $\|$ The concentration of surfactant phospholipid $10 \mu \mathrm{mol} / \mathrm{ml}$.

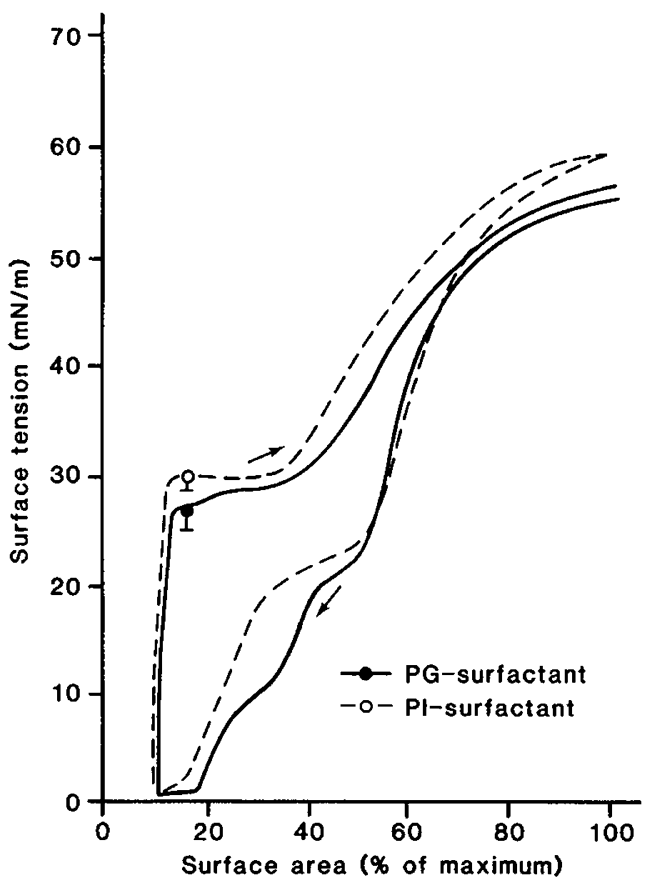

Fig. 2. Surface area-surface tension isotherms of PG and PI surfactants. The surface tension during expansion cycle (mean \pm SD of seven measurements in each group) indicates a minor difference between PG and PI surfactants.

could have modified the surface properties. Therefore, there was still a possibility that PI surfactant had surface properties inferior to those of normal PG surfactant, and a comparison of the two types, both originating from adult lungs, seemed pertinent.

Our study demonstrated that both types of surfactant in vitro exhibited the following important properties (24): 1) a rapid adsorption from subphase to surface, 2) a minimal surface tension of 0 to $4 \mathrm{mN} / \mathrm{m}$ on compression of the surface, 3) a compressibility considerably less than the $0.09 \mathrm{mN} / \mathrm{m}$ at low surface tension $(<15 \mathrm{mN} / \mathrm{m}), 4)$ a slow collapse of the maximally compressed film toward the equilibrium surface tension, 5) a wide hysteresis loop observed with the Wilhelmy balance. Our observation that the surface properties of PG and PI surfactants were only marginally different was in accord with a previous report (4), and there was no clear evidence that one was superior to the other. Of several parameters analyzed, the only difference observed was a slightly higher recruitment index (33) of the PI surfactant. This minor difference is not necessarily due to the acidic phospholpids, and its effect was not noticeable on the compliance of premature rabbit lungs. The pressure-volume relationship was equally improved by the two types of surfactant (4). Our data are in accord with those reported by Beppu et al. (4) who also found a similarity in the ultrastructure of normal and PG-deficient surfactant. Both surfactant suspensions contained tubular myelin. It would seem, from our results and those of others, that PI can substitute for PG without affecting normal surfactant function.

The role of the acidic phospholipids is not clearly understood, but present evidence indicates that PG improves the function of saturated PC. The collapse of a DPPC film, occurring during compression, can be prevented by the presence of PG in the monolayer (2). This may explain why surfactant PG improves the stability of surfactant PC at low surface tension (22). PG may also affect the adsorption rate, in that the poor adsorption of a liposome suspension prepared from DPPC only, is effectively improved by the inclusion of PG (34). These effects of PG, detected with physical methods, may explain why PG to some extent improves the surface properties of DPPC during a surfactant substitution $(21,30)$. However, it is evident that also other lipids, especially PI, improve the function of the major surfactant phospholipid $(21,22,28,32,37)$, and so far there is no convincing evidence to indicate tht PG is superior to PI as a component of an artificial surfactant $(12,22,25,28,34)$.

Our results do not exclude the possibility that PG has an 

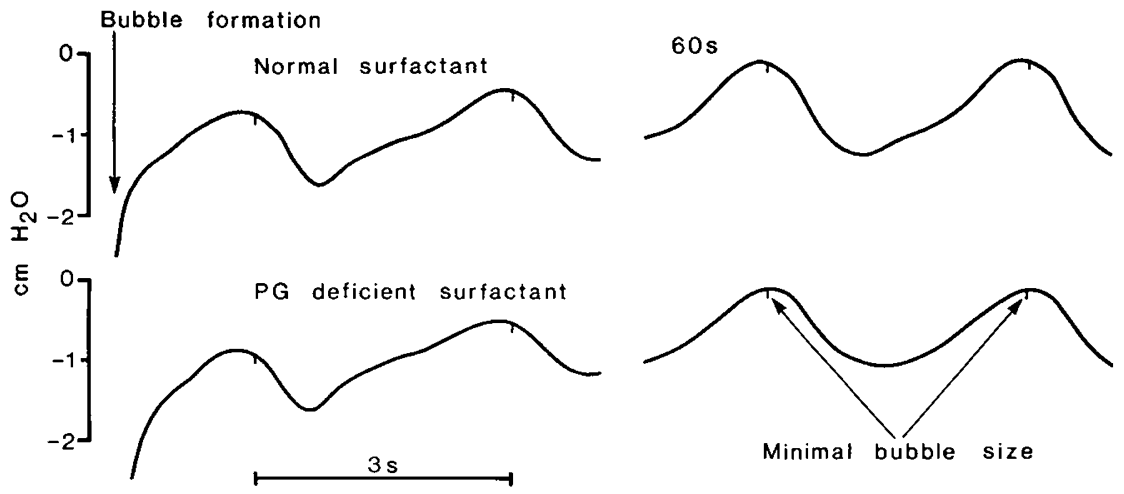

Fig. 3. Pressure tracing obtained with the pulsating bubble surfactometer when the bubble was pulsating in normal and PG-deficient surfactant ( $2 \mu \mathrm{mol}$ phospholipid/ml). Fast adsorption was noted with both types and, 1 min after bubble formation, surface tension was close to zero at minimal bubble size.

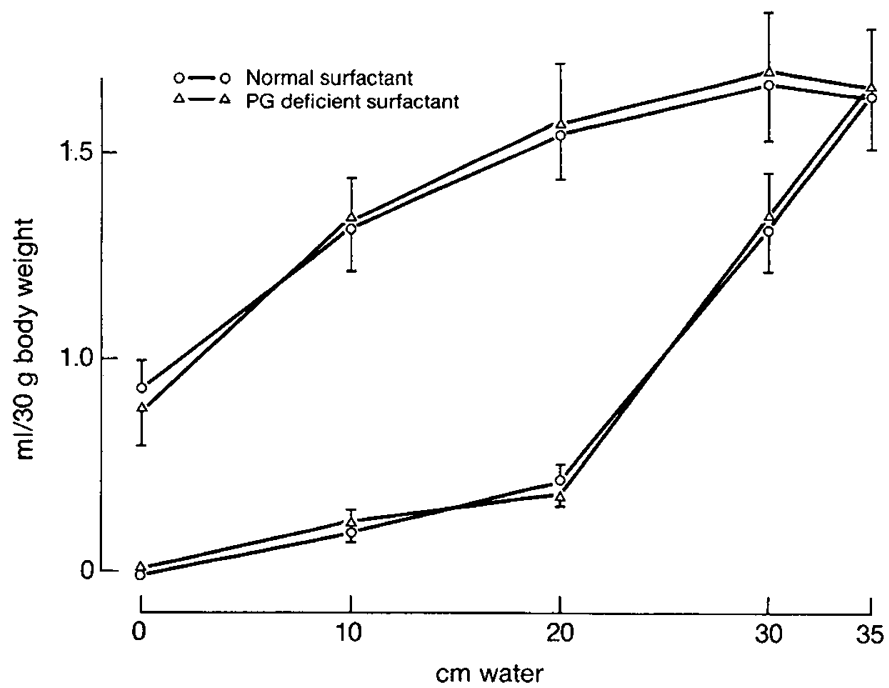

Fig. 4. Pressure volume loops from preterm rabbit neonates given a tracheal instillation of normal $(n=24)$ and PG-deficient $(n=25)$ surfactant. Lung compliance was equally affected by the two types of surfactant. Instillation of saline without surfactant into the airways allowed a maximum of $0.4 \pm 0.3 \mathrm{ml} / 30 \mathrm{~g}$ of air entry and less than 0.1 $\mathrm{ml} / 30 \mathrm{~g}$ of air retention at $0 \mathrm{~cm} \mathrm{H}_{2} \mathrm{O}$.

important role in lipid metabolism; in fact, there would seem to be a difference in the ability of PI and PG to affect the synthesis (11) as well as the intracellular transport and secretion (17) of surfactant.

A remarkable finding of the present study was that myoinositol treatment for 4 days not only alters the acidic phospholipids but also significantly increases the alveolar surfactant pool. Interestingly, myoinositol also increases the synthesis and secretion of surfactant PC during hormone-induced fetal lung maturation (15). This consequence of the high fetal serum (extracellular) myoinositol would seem to be beneficial. However, in healthy individuals there are no known benefits attributable to an increase of the surfactant pool. Furthermore, excess myoinositol may have damaging effects on other organ systems. In vitro myoinositol has been shown to promote the growth of malignant as well as normal cells (8), and it has been proposed that myoinositol excess may cause neuropathy $(7,14)$. If myoinositol is ever considered for therapy to promote surfactant synthesis, these potential side effects must be taken into consideration.

\section{REFERENCES}

1. Arvidson GAE 1968 Structural and metabolic heterogeneity of rat liver glycerophosphatides. Eur J Biochem 4:478
2. Bangham AD, Morley CJ, Phillips $M C 1979$ The physical properties of an effective lung surfactant. Biochim Biophys Acta 573:552

3. Batenburg JJ, Klazinga W, Van Golde LGM 1982 Regulation of phosphatidylglycerol and phosphotidylinositol synthesis in alveolar type II cells isolated from adult rat lung. FEBS Lett 147:171

4. Beppu OS, Clements JA, Goerke J 1983 Phosphatidylglycerol-deficient lung surfactant has normal properties. J Appl Physiol 55:496

5. Bleasdale, JE, Maberry MC, Quirk LG 1982 Myoinositol homeostasis in fetal rabit lung. Biochem $J$ 206:43

6. Burton LE, and Wells WW 1974 Studies on the developmental pattern of the enzymes converting glucose 6-phosphate to myoinositol in the rat. Dev Biol $37: 35$

7. De Jesus PV, Clements RS Jr, Winegrad AI. 1974 Hypermyoinositolemic polyneuropathy in rats: A possible mechanism for uremic neuropathy. $J$ Neurol Sci 21:237

8. Eagle H, Oyama CI, Levy M, Freeman AE 1957 Myo-Inoitol as an essential growth factor for normal and malignant human cells in tissue culture. J Biol Chem 226:191

9. Enhorning $G 1977$ Pulsating bubble technique for evaluating pulmonary surfactant. J Appl Physiol 43:198

10. Enhorning G, Robertson B 1972 Lung expansion in the premature rabbit fetus after tracheal deposition of surfactant. Pediatrics 50:58

11. Feldman DA, Kovac CR Dranginis PL, Weinhold PA 1978 The role of phosphatidylglycerol in the actication of CTP: phosphocholine cytidylyltransferase from rat lung. $J$ Biol Chem 253:4980

12. Fujiwara T, Tanake Y, Takei T 1979 Surface properties of artificial surfactant in comparison with natural and synthetic surfactant lipids. Int Res Commun Sys Med Sci 3:311

13. Gluck L, Sribney M, Kulovich MV 1967 The biochemical development of surface activity in mammalian lung. II. The biosynthesis of phospholipids in the lung of the developing rabbit fetus and newborn. Pediatr Res 1:247

14. Greene DA, De Jesus PC, Winegrad AI 1975 Effect of insulin and dietary myoinositol on impaired peripheral motor nerve conduction velocity in acute streptozotocin diabetes. J Clin Invest 55:1326

15. Hallman M 1984 Interaction of extracellular myoinositol with surfactant phospholipid synthesis in the fetal rabbit lung. Biochim Biophys Acta 795:67

16. Hallman M, Epstein BL 1980 Role of Myo-Inositol in the synthesis of phosphatidylglycerol and phosphatidylinositol in the lung. Biochem Biophys Res Commun 92:1151

17. Hallman M, Epstein BL, Gluck L 1981 Analysis and labeling and clearance of lung surfactant phospholipids in rabbit. Evidence of bidirectional surfactant flux between lamellar bodies and alveolar lavage. J Clin Invest 68:742

18. Hallman M, Gluck L 1976 Phosphatidylglycerol in lung surfactant. III. Possible modifier of surfactant function. J Lipid Res 17:275

19. Hallman M, Gluck L 1980 Formation of acidic phospholipids in rabbit lung during perinatal development. Pediatr Res 14:1250

20. Hildebran JN, Goerke J, Clements JA 1979 Pulmonary surface film stability and composition. J Appl Physiol 47:604

21. Ikegami M, Silverman J, Adams FH 1979 Restoration of lung pressure-volume characteristics with various phospholipids. Pediatr Res 13:777

22. Jacob J, Hallman M, Gluck L 1980 Phosphatidylinositol and phosphatidylglycerol enhance surface active properties of lecithin. Pediatr Res 14:644A

23. King R 1982 Pulmonary surfactant. J Appl Physiol 53:1

24. King RJ, Clements JA 1972 Surface active materials from dog lung. II. Composition and physiological correlations. Am J Physiol 223:715

25. King RJ, MacBeth MC 1981 Interaction of the lipid and protein components of pulmonary surfactant. Role of phosphatidylglycerol and calcium. Biochim Biophys Acta 647:159

26. Kuksis A, Marai WC, Breckenridge DA, Gornall DA, Stachnyk O 1968 Molecular species of lecithins of some functionally distinct tissues. Can J Physiol Pharmacol 46:511

27. Mason RJ, Nellenbogen J, Clements JA 1976 Isolation of disaturated phosphatidylcholine with osmium tetroxide. J Lipid Res 17:281 
28. Metcalfe IL, Enhorning G, Possmayer F 1980 Pulmonary surfactant-associated proteins: their role in the expression of surface activity. J Appl Physiol 49:34

29. Michell RH 1975 Inositol phospholipids and cell surface receptor function. Biochim Biophys Acta 415:81

30. Morley C, Robertson B, Lachmann B, Nilsson R, Bangham A 1980 Artificial surfactant and natural surfactnt: comparative study of the effect on premature rabbit lungs. Arch Dis Child 55:758

31. Nixon DA 1968 The concentration of free myo-inositol in the plasma of perfused sheep fetuses. Biol Neonate 12:113

32. Notter RH, Tabak SA, Mavis RD 1980 Surface properties of binary mixtures of some pulmonary surfactant compoents. J Lipid Res 21:10

33. Notter RH, Taubold R, Mavis RD 1982 Hysteresis in saturated phospholipid films and its potential relevance for lung surfactant function in vivo. Exp Lung Res 3:109

34. Obladen M, Popp D, Schöll C, Schwartz H, Jähnig F 1893 Studies on lung surfactant replacement in respiratory distress syndrome. Rapid film formation from binary mixed liposomes. Biochim Biophys Acta 735:215

35. Okano G, Akino T 1979 Variations in the molecular species of lung phosphatidylglycerol. Lipids 14:541

36. Renkonen O 1966 Individual molecular species of phospholipids. III. Molecular species of ox-brain lecithins. Biochim Biophys Acta 125:288

37. Tanaka J, Takei T, Kanazawa Y 1983 Lung surfactants. II. Effects of fatty acids, triacylglycerols and protein on the activity of lung surfactant. Chem Pharm Bull 31:4100

\title{
Postheparin Plasma Lipases and Carnitine in Infants during Parenteral Nutrition
}

\author{
LIISA ROVAMO \\ Children's Hospital and Third Department of Medicine, University of Helsinki, Helsinki, Finland
}

\begin{abstract}
Lipoprotein lipase is the rate-limiting factor for hydrolyzing triglycerides to glyerol and fatty acids. Carnitine is a cofactor in the transport of long-chain fatty acids through the mitochondrial membrane for oxidation. To assess these determinants of fat utilization during total parenteral nutrition, lipoprotein and hepatic lipase activities and carnitine concentrations of nine newborn infants, operated on because of gastrointestinal anomalies during the first day of life, were measured with specific methods. Total parenteral nutrition was built up in 3 days whereafter the infants received $3 \mathrm{~g} / \mathrm{kg}$ of fat at a constant rate of infusion for $24 \mathrm{~h} /$ day. Lipoprotein lipase activity of postheparin plasma increased from 14 to $35 \mu \mathrm{mol}$ free fatty acids $/ \mathrm{ml} / \mathrm{h}$ during parenteral nutrition whereas hepatic lipase activity remained unchanged at $\mathbf{4 0} \mu \mathrm{mol}$ free fatty acids $/ \mathrm{ml} / \mathrm{h}$. Serum free carnitine and acylcarnitine levels decreased significantly during parenteral nutrition; urinary excretion of carnitine decreased also. In addition, serum cholesterol and phospholipids increased markedly during parenteral nutrition whereas serum triglycerides, free fatty acids, and blood $\beta$-hydroxybutyrate remained unchanged. Serum apolipoprotein A-I concentrations were unaltered, apolipoprotein A-II underwent a transient increase, and apolipoprotein $B$ increased monotonically during parenteral nutrition. The results suggest that under the present circumstances neither lipoprotein lipase activity nor carnitine resources are rate-limiting for the utilization of fat in newborn infants during total parenteral nutrition. (Pediatr Res 19: 292-296, 1985)
\end{abstract}

Received April 5, 1984; accepted October 24, 1984.

Requests for reprints should be addressed to Liisa Rovamo, M.D., Children's Hospital, University of Helsinki, 00290 Helsinki 29, Finland.

This research was supported by Foundation for Pediatric Research, Huhtamäki OY Leiras Pharmaceuticals, Hilma and Heikki Honkanen's Foundation, Foundation of Nutritional Research, the Finnish Academy, Finnish Foundation for Culture, Sigrid Juselius Foundation, and Nordisk Insulinfond.
Lipoprotein lipase is the rate-limiting factor for clearance of fat from the circulation; it hydrolyzes triglycerides of lipoproteins and fat emulsion particles to glycerol and free fatty acids $(4,19)$. Carnitine is essential for facilitated transport of long-chain free fatty acids across the mitochondrial membrane (9).

Lipoprotein lipase in newborn infants is usually estimated by determining postheparin plasma lipolytic activity $(6,8)$. Postheparin plasma, however, contains hepatic lipase too $(14,26)$. The function of hepatic lipase is unsettled $(11,15,16,18,19)$ but its activity in infants is about three times the activity of lipoprotein lipase $(26,27)$. In addition, these two lipases can vary independently $(26,27)$. Hence, postheparin plasma lipolytic activity is an inadequate measure of lipoprotein lipase.

Adults can synthesize the carnitine they need. Therefore, carnitine is not considered an essential nutrient. Newborn infants may not, however, be capable of sufficient carnitine synthesis. Therefore, infants may be dependent on nutritional sources of carnitine, such as milk. Infants receiving carnitine-free total parenteral nutrition are at risk of developing carnitine deficiency characterized by decreased blood concentration and tissue content of carnitine $(2,20,24,28)$. Reduced carnitine intake may impair fatty acid oxidation and diminish ketogenesis after fat infusion; these deficiencies can be corrected with supplementary carnitine $(23,29)$.

To study the role of the principal regulators of fat metabolism in newborn infants lipoprotein lipase and hepatic lipase activities and carnitine concentrations were measured during parenteral nutrition.

\section{PATIENTS AND METHODS}

Patients. The patients were nine newborn infants who required surgical operation and parenteral nutrition because of gastrointestinal tract anomalies (Table 1). Surgery was performed under general anesthesia during the first day of life. For subsequent parenteral nutrition seven infants received central venous catheters and two infants (patients 4 and 5) peripheral venous catheters; none had a continuous heparin infusion. After the opera- 